\title{
BMJ Open Obstacles to diagnosis and treatment of Lyme disease in the USA: a qualitative study
}

\author{
Annemarie G Hirsch, ${ }^{1}$ Rachel J Herman, ${ }^{2}$ Alison Rebman, ${ }^{3}$ Katherine A Moon, ${ }^{4}$ \\ John Aucott, ${ }^{3}$ Christopher Heaney, ${ }^{4,5}$ Brian S Schwartz ${ }^{1,4}$
}

To cite: Hirsch AG, Herman RJ, Rebman A, et al. Obstacles to diagnosis and treatment of Lyme disease in the USA: a qualitative study. BMJ Open 2018;8:e21367. doi:10.1136/ bmjopen-2017-021367

- Prepublication history for this paper is available online. To view these files please visit the journal online (http://dx.doi org/10.1136/bmjopen-2017021367).

Received 8 January 2018 Revised 4 May 2018 Accepted 18 May 2018

Check for updates

${ }^{1}$ Department of Epidemiology and Health Services

Research, Geisinger, Danville,

Pennsylvania, USA

${ }^{2}$ Gettysburg College, Gettysburg, Rhode Island, USA

${ }^{3}$ Department of Medicine,

Division of Rheumatology, Johns Hopkins University, School of Medicine, Baltimore, Maryland, USA

${ }^{4}$ Department of Environmental Health and Engineering, Johns Hopkins University Bloomberg School of Public Health, Baltimore, Maryland, USA ${ }^{5}$ Department of Epidemiology, Johns Hopkins University Bloomberg School of Public Health, Baltimore, Maryland, USA

Correspondence to Dr Annemarie G Hirsch; aghirsch@geisinger.edu

\section{ABSTRACT}

Objective For many individuals with Lyme disease, prompt treatment leads to rapid resolution of infection. However, severe complications can occur if treatment is delayed. Our objective was to identify themes around belated diagnosis or treatment of Lyme disease using the General Model of Total Patient Delay (GMTPD).

Design We conducted a qualitative interview study using indepth telephone interviews.

Setting Participants were patients from a large, integrated health system in the state of Pennsylvania, USA.

Participants There were 26 participants. Participants had to have a diagnosis of Lyme disease between 2014 and 2017 and a positive IgG western blot. We used a stratified purposeful sampling design to identify patients with and without late Lyme disease manifestations. To ensure variation in care experiences, we oversampled patients diagnosed outside of primary care.

Outcome measures We asked participants about their experience from first Lyme disease symptoms to treatment. We applied an iterative coding process to identify key themes and then synthesised codes into higher order codes representing the GMTPD stages: appraisal delay (symptom to recognition of illness); illness delay (inferring illness to deciding to seek help); behavioural delay (deciding to seek help to the act of seeking help); scheduling delay (seeking help to attending an appointment); and treatment delay (attending appointment to treatment).

Results Appraisal delay themes included symptom misattribution, intermittent symptoms and misperceptions about the necessity of a bull's-eye rash. Health insurance status was a driver of illness and behavioural delays. Scheduling delay was not noted by participants, in part, because 10 of the 26 patients went to urgent care or emergency department settings. Misdiagnoses were more common in these settings, contributing to treatment delay. Conclusion Our study identified potentially modifiable risk factors for belated treatment. Targeting these risk factors may minimise time to treatment and reduce the occurrence of preventable complications.

\section{INTRODUCTION}

Lyme disease is a tick-borne infectious disease that is on the rise in the Northeast, Mid-Atlantic and Upper Midwest regions of the USA. ${ }^{1}$ Delays in diagnosis or treatment

\section{Strengths and limitations of this study}

To our knowledge, this is the first study to examine which factors account for belated treatment of Lyme disease.

- Through the lens of the General Model of Total Patient Delay, a widely used model that describes the decisional processes and potential delays prior to treatment, we identified distinct phases between onset of first Lyme disease symptoms and Lyme disease treatment.

- This study was conducted in a well-defined sample of participants who had both a Lyme disease diagnosis and a positive lgG western blot.

- The study was conducted in a health system in the USA; therefore, some findings may not be generalisable to other countries due to differences in factors such as healthcare cost and access.

- While our eligibility criteria were highly specific for Lyme disease, requiring a positive IgG western blot may have excluded patients who received care in the first few weeks of infection, when the test is expected to be negative.

(hereafter referred to as belated treatment) of Lyme disease can lead to preventable complications, representing later stages of the disease when the infection disseminates, including neurological manifestations, cardiac abnormalities and arthritis. ${ }^{2}$ While little is known about the prevalence of belated treatment in Lyme disease, the observation that $32 \%$ of Lyme disease cases are diagnosed with arthritis, $12 \%$ with neurological conditions and $1 \%-2 \%$ with carditis ${ }^{2}$ suggests that belated treatment may occur in as many as $40 \%$ of cases. To date, the study of time to treatment has largely focused on cancer and cardiovascular events. ${ }^{3}$ No study has examined which factors account for belated treatment of Lyme disease, despite the benefits of prompt treatment of this disease.

The General Model of Total Patient Delay $(\mathrm{GMTPD})^{4}$ is a widely used, five-stage model that describes the decisional processes and 
potential delays prior to treatment. ${ }^{3}$ Appraisal delay is the time between when a person first notices an unexplained symptom until the person concludes he/she is ill. Appraisal has generally been found to be the key determinant in delay in seeking help. ${ }^{3}$ Illness delay is the time between inferring the illness and deciding to seek help; behavioural delay represents the time between deciding an illness requires medical care and acting; scheduling delay is the time between deciding to seek help and attending an appointment; and treatment delay is the time between the first appointment with a healthcare provider and onset of treatment. ${ }^{4}$ While this model has been widely applied to cancer and myocardial infarction, it has not been applied to Lyme disease. Thus, the primary drivers of belated treatment in Lyme disease remain unknown.

To identify themes around belated treatment, as well as to evaluate the application of the GMTPD to Lyme disease, we interviewed 26 patients with a diagnosis of Lyme disease to gain insight into their experiences between onset of Lyme disease symptoms and treatment. Such understanding is critical to informing strategies that would reduce time to diagnosis and treatment and prevent late-stage Lyme disease.

\section{METHODS}

We conducted a qualitative study using indepth telephone interviews of Geisinger patients with a Lyme disease diagnosis to understand what happens between the onset of Lyme disease symptoms and treatment. We analysed interview findings through the GMTPD framework.

\section{Study setting and sample}

We identified study participants using the electronic health record from Geisinger, an integrated health system servicing more than 45 counties in Pennsylvania and New Jersey, USA, both high-incidence states for Lyme disease. ${ }^{5}$ Patients were eligible if they were at least 18 years of age; had an International Classification of Disease code (ICD-9: 088.81 or ICD-10: A69.20) for Lyme disease associated with at least one clinical encounter between 2014 and 2017; and an IgG western blot meeting the Centers for Disease Control and Prevention criteria of five or more positive bands. ${ }^{6}$ We used a stratified purposeful sampling design to identify patients with and without late Lyme disease manifestations: Lyme arthritis (ICD-9: 711.8x; ICD-10: M01.X0); facial palsy (ICD-9: 351.0, 352.9; ICD-10: G51.0, G52.9); meningoencephalitis (ICD-9: 320.7; ICD-10: G01); or myocarditis (ICD-9: 422.0; ICD-10: I41). To ensure variation in care experiences, we oversampled patients diagnosed outside of primary care. We first sent letters to notify 93 patients (47 with late manifestations and 46 without) that they were eligible for the study. Two weeks later we telephoned patients to schedule a telephone interview. Participants who completed an interview received a $\$ 50$ gift card. Recruitment continued until data saturation, the point at which no new information seemed to emerge during coding. ${ }^{7}$

\section{Data collection}

We conducted indepth, semistructured, open-ended telephone interviews between August and September 2017, each lasting approximately $30 \mathrm{~min}$. Telephone interviews allowed for capture of patient experiences across the large geographical area served by Geisinger. Geisinger's Institutional Review Board waived the requirement of written consent after determining that the study posed no more than minimal risk of harm to participants. An experienced interviewer (first author AGH) obtained verbal consent and asked participants to talk about their experience with Lyme disease, from symptom onset to treatment. The interviewer was a researcher employed by the health system that treated participants for Lyme disease. To address any potential concerns participants might have had in describing their care experiences to a health system employee, the interviewer informed participants that their responses would not impact the care received at Geisinger and would be kept confidential. The interviewer then used an interview guide to follow up on the account that included questions in six primary areas: Lyme disease knowledge, pretreatment symptoms, care-seeking behaviour, diagnosis process, treatment process and post-treatment symptoms. All interviews were audio-recorded and transcribed verbatim. No additional field notes were recorded. We did not return transcripts to participants for comment or correction.

\section{Analysis}

We applied a deductive content analysis of interview transcripts, based on the GMTPD. ${ }^{8}$ We applied an iterative coding process to identify themes corresponding to the six primary areas, as well as emergent themes. After the first five interviews, one of two coders reviewed the transcripts to develop a preliminary coding framework. A second coder then applied the framework to the same five interviews. The coding team (two members) discussed the findings and reached consensus on an updated coding scheme, revising the scheme as new themes emerged. The coding team also updated the interview guide to incorporate questions around emergent themes for future interviews. In the final phase of analysis, the coders developed higher order categories representing the five delay stages of the GMTPD. Analysis was conducted using Atlas.ti V.7.

\section{Patient and public involvement}

Patients were not involved in the development of the research question, the design, recruitment or conduct of this study. The results of this study will be disseminated to study participants via letter and disseminated to patients via health system print newsletters and social media outlets. 


\section{RESULTS}

Out of the 93 patients to whom we sent a letter, we telephoned 56 patients and reached 33. Of these, 26 (79\%) agreed to be interviewed. We stopped recruitment calls after reaching saturation. While the interviews were intended to be one-on-one, two patients had a spouse with them in the room during the interview. In one case, a spouse joined the call. However, analysis was confined to the information presented by the 26 patients.

Slightly more than half of the participants were female, $30 \%$ had a history of being on medical assistance (a surrogate for low family socioeconomic status) ${ }^{9}$ and participants ranged in age from 22 to 70 years (table 1). Half of the participants first sought care for Lyme disease from a primary care provider and $38.5 \%$ first went to an urgent care centre or emergency department.

Ten participants reported that they had a rash, three of whom described the rash as a bull's-eye. Five of the participants who reported a rash sought care because of the rash. The remaining did not seek care until other symptoms (eg, fatigue, joint pain) appeared. Two of the five participants who saw a doctor because of the rash were initially misdiagnosed. Eleven participants reported having joint pain, although patients did not specify whether the joint pain was diagnosed as Lyme arthritis. Eight patients reported having Bell's palsy, two patients reported carditis and one patient reported a diagnosis of Lyme meningitis.

A number of themes emerged regarding seeking care for Lyme disease symptoms. We classified these themes into one of the five GMTPD stages (table 2).

Participants reported seeking care both within and external to Geisinger for their initial Lyme disease symptoms, but we did not ask in which healthcare system delays occurred.

\section{GMTPD stages}

\section{Appraisal delay}

Participants consistently reported an appraisal delay, a gap between their first symptom and recognition that they were ill (table 2). Some participants attributed this gap to the inconsistent nature of their symptoms. One participant explained:

I was just having occasional joint achiness where it kind of felt like I slept funny on my elbow. It would be sore for a day or two and then it would go away.

Patients also misattributed symptoms to minor injuries, pre-existing conditions or influenza. One participant noted: "I also have fibromyalgia, so it's kind of hard to differentiate."

Patients ruled out Lyme disease in the absence of the bull's-eye rash perceived to be characteristic of Lyme disease, delaying medical attention even in the presence of a rash. One participant explained:

And then I got a like this rash on my legs, on my arms, on my back. It was really bad. And I didn't
Table 1 Characteristics and Lyme disease symptoms and diagnosis patterns of participants $(n=26)$

\begin{tabular}{|lr|}
\hline Age, years, $\mathrm{n}(\%)$ & $9(34.6)$ \\
\hline $18-39$ & $11(42.3)$ \\
\hline $40-64$ & $6(23.1)$ \\
\hline $65+$ & $14(53.8)$ \\
\hline Female, $\mathrm{n}(\%)$ & \\
\hline Race/ethnicity, $\mathrm{n}(\%)$ & $26(100)$ \\
\hline White, non-Hispanic & $8(30.1)$ \\
\hline Ever received medical assistance, $\mathrm{n}(\%)$ & \\
\hline Rash, $\mathrm{n}$ (\%) & $3(11.5)$ \\
\hline 'Bull's-eye' rash & $7(26.9)$ \\
\hline Other rash & $16(61.5)$ \\
\hline No rash & \\
\hline First symptom/condition recalled ${ }^{\star}, \mathrm{n}(\%)$ & $8(30.8)$ \\
\hline Joint pain/swelling & $4(15.4)$ \\
\hline Rash & $4(15.4)$ \\
\hline Fatigue & $3(11.5)$ \\
\hline Headache & $1(3.8)$ \\
\hline Bell's palsy & $7(26.9)$ \\
\hline Other† & $1(3.8)$ \\
\hline No symptom recalled & \\
\hline Symptom/conditin that triggered first contact with & \\
\hline
\end{tabular}

Symptom/condition that triggered first contact with medical provider, $\mathrm{n}(\%)$

\begin{tabular}{|c|c|}
\hline Joint pain & $9(34.6)$ \\
\hline Rash & $5(19.2)$ \\
\hline Fatigue & $3(11.5)$ \\
\hline Bell's palsy & $2(7.7)$ \\
\hline Other $\neq$ & $5(19.2)$ \\
\hline $\begin{array}{l}\text { No symptom recalled-rash discovered during } \\
\text { clinic visit for other conditions }\end{array}$ & $2(7.7)$ \\
\hline \multicolumn{2}{|l|}{ Self-reported Lyme-related diagnoses, n (\%) } \\
\hline $\begin{array}{l}\text { Joint pain (diagnosis of Lyme arthritis not } \\
\text { specified) }\end{array}$ & $10(38.5)$ \\
\hline Bell's palsy & $8(30.7)$ \\
\hline Carditis & $2(7.7)$ \\
\hline Meningitis & $1(3.8)$ \\
\hline \multicolumn{2}{|l|}{ First medical care provider contacted, n (\%) } \\
\hline Urgent care/emergency department & $10(38.5)$ \\
\hline Primary care provider & $13(50.0)$ \\
\hline Other & $3(11.5)$ \\
\hline Misdiagnosed by medical provider, $\mathrm{n}(\%)$ & $9(34.6)$ \\
\hline \multicolumn{2}{|c|}{ Medical care provider who misdiagnosed§, $\mathrm{n}$ (\% of misdiagnoses } \\
\hline Urgent care/emergency department (both) & $7(77.8)$ \\
\hline Primary care provider & $4(44.4)$ \\
\hline
\end{tabular}

*The total is greater than 26 because one participant reported pain and rash occurred at the same time.

†Other symptoms: vomiting; shortness of breath; aches/pains, not specific to joints (3); and tick bite.

‡Other symptoms: vision change (2), stiff neck, vomiting and dizziness.

$\S$ The total is greater than 9 because two patients were misdiagnosed by both emergency department and primary care physician. 
Table 2 Participant quotes regarding the General Model of Total Patient Delay stages

Stage/domain
Appraisal
my legs."

Misattribution
"I got a new computer, and I thought that it was not positioned correctly and because I was just on the computer
pretty much all day and maybe thought I strained my neck."
"I was just kind of dealing with it because I thought maybe I slept on it [elbow] wrong or something."
"My joints hurt, but I have rheumatoid arthritis, so I never associated it with Lyme disease, because I've had
rheumatoid arthritis for many years, and I thought I was just getting another flare, so all the symptoms for my joint
pain, I just associated with my rheumatoid condition."
"I didn't think of Lyme, because it was it wasn't a bull's eye at all."
"And it started growing and growing and, interestingly enough, it didn't assume the kind of quintessential bull's eye
pattern. I always jokingly refer to it as a political boundary. It looked more like a map of the world, it was very, while it
was roughly circular in shape, it was very jutted...looked more like Antarctica on my arm."
"Because, you know, we kind of live in the country, you hear about it and knew a couple people that had had it, but
they had all, you know, had gotten the typical symptoms of, you know, the red bulls-eye."

IIIness/behavioural delay

Health insurance "So, I mean I just did as good as I could [to get the tick out]... but I wasn't sure that I got it all and I didn't have insurance at the point, so I didn't bother to go to the doctor. So, I just let it go, figured I wait and see, stupid idea."

- "I didn't have insurance. That was one of the main things. And, like I said, I was young, and I was just starting a new job, so I didn't have a lot of money. So, I was like, I don't know how I'll pay for that."

Treatment delay

Emergency department and "I saw my primary care physician about two weeks later [after emergency department visit.] And that's when she told urgent care settings me that I had the Lyme disease and then she said they [emergency department] had suspected it while I was in the emergency room, and nothing was ever given to me then. The test was done in the ER. Because I remember she [primary care physician] was mad that nobody there had contacted me and she said they, you know, could've gotten me started sooner on the medication."

- "I went up to the ER and they told me I had bursitis. Either bursitis or tendonitis. And told me that I'm to check back if I have any more issues. Well, it was still excruciating I went back before the week was up. That's when they told me I had the opposite, either bursitis or tendonitis. One of them. One or the other was, they thought the issue was, well it never went away. My doctor was out on vacation and I had called the office and...I said when she gets back, I need to see her ASAP. So, she had called and she got a hold of me and went back down into the office and as soon as she came in, she told me right away, I bet you have Lyme disease."

even know about Lyme disease at that time...I mean I knew that you'd get a bull's-eye rash. And it wasn't that, so I went to the doctor probably about... at least three weeks later.

\section{IIIness delay/behavioural delay}

Generally, once patients decided to seek medical care (illness delay), they acted on the decision (behavioural delay). One of the 26 participants noted a gap of 5 or 6 days between deciding he needed medical care and seeking care due to health insurance:

Every hour or so I would take my temperature and it was just going up and up... And I didn't have insurance. And I thought I have to make it to Monday, because Monday is when my insurance was going to kick in. I said I have got to survive until Monday. I mean I would have went that Wednesday or Thursday that I was so sick. I had called somebody I know that's a nurse and she said, 'I don't want you to die on me but get in your bed and don't frickin' move,... until Monday if you can make it'. So, I, I took the words she said to heart and just kind of didn't move the entire weekend.
While no other patients articulated this gap between deciding to seek care and acting on it, health insurance was the most commonly occurring theme regarding the delay in deciding whether to seek medical attention for their symptoms (table 2).

\section{Scheduling delay}

Scheduling delay did not emerge as a problem for any of the participants. Ten of the 26 participants initially sought care for symptoms at an urgent care or emergency department setting. Some of these patients noted that they decided to seek medical attention at these establishments because of the weekend and evening hours.

\section{Treatment delay}

When present, delays between the first appointment with a healthcare provider about Lyme disease symptoms and treatment were generally reported to be the result of a misdiagnosis (eg, cellulitis). Nine of the 26 participants $(34.6 \%)$ reported that they were not diagnosed with Lyme disease at their first contact with a medical professional regarding Lyme disease symptoms. Seven of these nine participants $(77.8 \%)$ reported a misdiagnosis that occurred at an urgent care or emergency department 
setting, representing $70 \%$ of patients who first sought care in these settings (table 2). One participant described this experience:

No, they [emergency department] didn't do any blood tests...Kind of examined and kind of listened to me. It was very busy that night. I know there was 1 or 2 doctors on and they had a bunch of drunks they were taking care of and things, so I think they may have missed the boat. ...the nurse tells my wife, 'You know I think you got to watch because', I think she said, 'I think there's more here than what it appears'. But that was it, and then they discharged me.

\section{Non-GMTPD themes}

\section{Role of family}

In multiple stages of the GMTPD, the involvement of family prompted action leading to treatment of Lyme disease. Most commonly, family members prompted patients to call the doctor (reducing illness/behavioural delay). For example:

I could no longer read the computer screen. I couldn't read the paper. And she (my wife) said, 'That's it, we're done playing around'. And I ended up at the doctors.

\section{Another example was:}

She (my sister) said to me, 'That (rash) doesn't look right'. And I said, 'Eh, it'll go away in a couple of days'. So, she told my mom, and my mom called me and said, 'I'm coming up to look at it. I think we should go to the doctor'. I said, 'Ma, it'll be fine'. She said, 'No, I think we should go'. So..., my sister calls and gets an appointment.

Family also played a role in reducing the treatment delay phase, after the patient saw a medical professional. In one instance, a patient was hospitalised for what was originally diagnosed as pain medication dependency. It was not until a family member demanded a transfer to a different hospital that Lyme disease was diagnosed.

So, I was there [at the hospital] for three or four days and all of the sudden I developed Bell's palsy. And they did a CAT scan and they determined it was not a stroke. I laid there five more days where they did nothing. My sister and mother came to visit. They would not have recognized me. My face was swollen and droopy. So my sister had me transferred to another hospital. Within hours I was diagnosed with neurological Lyme.

\section{Consequences of delays}

The original interview guide did not include questions regarding the impact of Lyme disease on work absenteeism/presenteeism or changes in productivity at work or home. However, the detrimental impact of Lyme disease on the ability to work and fulfil caregiving roles emerged as a common theme among participants.

I couldn't function, and I'm a care-taker for my mother, although she's a good 92 now... She took care of me, but I could not function. I lived on the sofa or in bed. That's how tired I was. If I tried to a do a little bit of anything, I would have to get back down, because I couldn't handle it.

Another person described a change in his work productivity before getting treated for Lyme disease.

I'd never sit down at work ever. I have my own machine shop. And I like nobody ever sees me sit. ... like it came to the point where I was sitting and then actually at lunchtime and stuff I would actually lay on the bench.

For some of these patients, the impact on work and caregiving persisted after treatment.

Yeah, yeah, I was off [work] for quite a while between them actually finally determining it was Lyme disease and the treatment and then the post check-up after the treatment to make sure I was fine. Yeah, I was probably off for at least two months, if not more.

A second patient explained:

I own my own business, I've been in business since 1990. It is definitely not the same. I have a hard time spelling words. I mean you got to go in, you got to sell yourself, you got to get all the work and, it's just tough anymore. I just don't have the, it's hard to put things together, you know what I mean, like on the fly. Like with words and everything. You seem to lose that edge and I don't know how to explain it. You know and everybody says, 'Oh you got old', but it just like changed instantly.

\section{DISCUSSION}

We conducted the first study, to our knowledge, to explore the experiences associated with the time between onset of symptoms and treatment of Lyme disease, with a specific focus on identifying themes related to belated treatment. Our study identified barriers to timely treatment that have been observed in other disease areas, as well as barriers specific to Lyme disease. We identified potential knowledge gaps in Lyme disease among patients and medical professionals, including misperceptions about the necessity of a bull's-eye rash. Understanding the conditions that participants perceive contribute to treatment delays can inform strategies that promote prompt treatment of Lyme disease, preventing dissemination of infection and the resulting disease complications.

Application of the GMTPD to Lyme disease was very instructive and showed that Lyme disease generally conformed to the model. The appraisal stage emerged as a distinct and dominant phase, as has been observed when 
this model has been applied to other diseases. ${ }^{3} 1011$ We identified three appraisal delay themes: symptom misattribution, intermittent symptoms and lack of bull's-eye rash. Both the intermittent nature of symptoms as well as the symptom misattribution to less serious or pre-existing conditions have been reported to account for appraisal delays in various cancers, particularly when the early symptoms were commonly occurring non-specific symptoms (eg, fatigue). ${ }^{12}{ }^{13}$ Specific to Lyme disease, respondents misattributed the joint pain of Lyme disease to other conditions with joint pain, such as rheumatoid arthritis and fibromyalgia.

Appraisal delays also resulted from a misunderstanding of the characteristic Lyme disease rash, erythema migrans. Specifically, participants reported that they did not suspect Lyme disease if they did not have a rash with central clearing, referred to as a bull's-eye rash. Approximately $20 \%-30 \%$ of people with Lyme disease do not present with erythema migrans, and among those who do have the rash, only $19 \%$ have the stereotypical bull's-eye appearance. ${ }^{14}$ The impact of the belief in the necessity of central clearing on belated treatment is compounded by the diagnostic challenges associated with Lyme disease in the absence of the rash. One study reported that $54 \%$ of patients with Lyme disease who did not have erythema migrans were initially misdiagnosed compared with $23 \%$ of patients who did have erythema migrans. ${ }^{15}$ Our findings highlight an important knowledge gap among patients regarding the skin manifestations of Lyme disease. Patient education campaigns that address this issue could reduce the time between infection and treatment.

The illness and behavioural delay stages appeared to be most influenced by health insurance status. Our findings are consistent with delays attributed to lack of health insurance observed in other disease areas. A lack of insurance has been associated with longer prehospital delays in myocardial infarction ${ }^{16} 17$ and with care-seeking behaviour in cancer. ${ }^{18}$ It is unknown whether the belated treatment due to lack of health insurance translates into an increased risk of late Lyme disease among the uninsured.

Scheduling delay was not a major contributor to belated treatment in our study, as nearly half of patients we interviewed sought care at emergency departments or urgent care centres, medical settings that typically offer same-day, evening and weekend appointments. While the availability of urgent care clinics and emergency departments appeared to minimise scheduling delays, the patients who first sought care at these locations reported more occurrences of misdiagnoses. Thus, the time saved in the scheduling delay stage by seeking care in one of these settings could be outweighed by the treatment delays resulting from misdiagnoses in these settings. The number of urgent care settings has dramatically increased over the last decade, but little is known regarding the quality of care for Lyme disease in these settings. ${ }^{19}$

Family interventions were identified to decrease the time to treatment in Lyme disease, consistent with the role of family and friends in belated treatment for cancer and cardiovascular disease. ${ }^{20} 21$ Smith and colleagues ${ }^{10}$ reported that, for many patients with cancer, friends and family helped with the process of illness attribution by observing or discussing vague symptoms with patients, ultimately making the connection between symptoms and illness that had gone unrecognised by the patient. The extent to which family structure, marital status and social support play a role in Lyme disease diagnosis and treatment has not been studied.

The impact of Lyme disease on work and caregiving activities emerged as a salient theme for participants, impacting patients prior to treatment and, in some cases, even after treatment. While costs occurring after a Lyme disease diagnosis have been studied, ${ }^{22}$ these studies do not account for the time between infection and treatment of disease, likely underestimating costs. Prior studies that focused on productivity loss and activity limitations in Lyme disease have been confined to individuals reporting symptoms persisting for more than 6 months. ${ }^{23}{ }^{24} \mathrm{~A}$ comprehensive study of indirect and direct costs across the full spectrum of Lyme disease, before and after treatment, would give a more complete picture of the individual and population-level burden of this disease.

To our knowledge, this is the first study to evaluate the application of GMTPD to Lyme disease. Through the lens of this model we identified distinct phases between onset of first Lyme disease symptoms and Lyme disease treatment. Our study was conducted in a well-defined sample of participants with a positive IgG western blot, a lab result present only at least $6-8$ weeks after Lyme disease infection. Our study had limitations. First, while our eligibility criteria were highly specific for Lyme disease, requiring a positive IgG western blot, patients may have been excluded as a result of false-negative test results that can occur at all stages of the disease, but most commonly among patients tested in the first few weeks of infection, when the test is expected to be negative. ${ }^{6526}$ Second, while our patients described interactions with health systems beyond Geisinger, all participants were tested for Lyme disease at Geisinger. With more than 44 Geisinger community practice sites and 12 hospital campuses across a large geographical region, there is likely a great deal of diversity in Lyme disease diagnosis and treatment experiences within the health system. However, these findings may not be generalisable to other countries due to differences in factors such as healthcare cost and access. Finally, the objective of this study was not to quantify the extent to which each delay phase contributed to belated treatment in Lyme disease. We identified several explanations for belated treatment of Lyme disease that are intervenable and can be targeted to minimise time to treatment and reduce the burden of Lyme disease on patients and society. To prioritise resources around secondary prevention strategies in Lyme disease, a large quantitative study on patients across the full spectrum of Lyme disease is needed both to determine how much each 
phase contributes to belated treatment and to quantify the degree to which factors increase the risk of belated treatment.

Contributors AGH, AR, KAM, JA, CH and BSS participated in the design of the study. AGH conducted data collection. AGH and RJH conducted data analysis. All authors participated in the writing of the manuscript.

Funding This work was supported by the Steven \& Alexandra Cohen Foundation. The Steven and Alexandra Cohen Foundation did not participate in data collection, analysis or the writing of this manuscript.

Competing interests None declared.

Patient consent Not required.

Ethics approval This study was approved by the Geisinger Institutional Review Board.

Provenance and peer review Not commissioned; externally peer reviewed.

Data sharing statement Interview guide and codebook available by request to the corresponding author.

Open access This is an open access article distributed in accordance with the Creative Commons Attribution Non Commercial (CC BY-NC 4.0) license, which permits others to distribute, remix, adapt, build upon this work non-commercially, and license their derivative works on different terms, provided the original work is properly cited and the use is non-commercial. See: http://creativecommons.org/ licenses/by-nc/4.0/

(C) Article author(s) (or their employer(s) unless otherwise stated in the text of the article) 2018. All rights reserved. No commercial use is permitted unless otherwise expressly granted.

\section{REFERENCES}

1. Nelson CA, Saha S, Kugeler KJ, et al. Incidence of ClinicianDiagnosed Lyme Disease, United States, 2005-2010. Emerg Infect Dis 2015;21:1625-31.

2. Mead PS. Epidemiology of Lyme disease. Infect Dis Clin North Am 2015;29:187-210.

3. Scott SE, Walter FM, Webster A, et al. The model of pathways to treatment: conceptualization and integration with existing theory. $\mathrm{Br} J$ Health Psychol 2013;18:45-65.

4. Andersen BL, Cacioppo JT. Delay in seeking a cancer diagnosis: delay stages and psychophysiological comparison processes. $\mathrm{Br} \mathrm{J}$ Soc Psychol 1995;34 (Pt 1):33-52.

5. Centers for Disease Control and Prevention. Lyme Disease: Data and statistics. 2016 https://www.cdc.gov/lyme/stats/index.html (accessed Oct 2017).

6. Centers for Disease Control and Prevention. Lyme Disease: Understanding the Immunoblot Test. 2015 https://www.cdc.gov/ lyme/diagnosistesting/labtest/twostep/westernblot/index.html (accessed Oct 2017).

7. Corbin J, Strauss A. Basics of Qualitative Research: Techniques and Procedures for Developing Grounded Theory. 3rd ed. Thousand Oaks, CA: Sage, 2008.
8. Elo $\mathrm{S}$, Kyngäs $\mathrm{H}$. The qualitative content analysis process. $J$ Adv Nurs 2008;62:107-15.

9. Casey JA, Pollak J, Glymour MM, et al. Measures of SES for Electronic Health Record-based Research. Am J Prev Med 2018;54:430-9.

10. Smith LK, Pope C, Botha JL. Patients' help-seeking experiences and delay in cancer presentation: a qualitative synthesis. Lancet 2005;366:825-31.

11. Evans $\mathrm{J}$, Ziebland $\mathrm{S}, \mathrm{McPherson} \mathrm{A}$. Minimizing delays in ovarian cancer diagnosis: an expansion of Andersen's model of 'total patient delay'. Fam Pract 2007;24:48-55.

12. Evans J, Chapple A, Salisbury H, et al. " It can't be very important because it comes and goes"-patients' accounts of intermittent symptoms preceding a pancreatic cancer diagnosis: a qualitative study. BMJ Open 2014;4:e004215.

13. Brouha XD, Tromp DM, Hordijk GJ, et al. Oral and pharyngeal cancer: analysis of patient delay at different tumor stages. Head Neck 2005;27:939-45.

14. Tibbles CD, Edlow JA. Does this patient have erythema migrans? JAMA 2007;297:2617-27.

15. Aucott J, Morrison C, Munoz B, et al. Diagnostic challenges of early Lyme disease: lessons from a community case series. BMC Infect Dis 2009;9:79.

16. Nguyen HL, Saczynski JS, Gore JM, et al. Age and sex differences in duration of prehospital delay in patients with acute myocardial infarction: a systematic review. Circ Cardiovasc Qual Outcomes 2010;3:82-92.

17. Smolderen KG, Spertus JA, Nallamothu BK, et al. Health care insurance, financial concerns in accessing care, and delays to hospital presentation in acute myocardial infarction. JAMA 2010;303:1392-400.

18. Rauscher GH, Ferrans CE, Kaiser K, et al. Misconceptions about breast lumps and delayed medical presentation in urban breast cancer patients. Cancer Epidemiol Biomarkers Prev 2010;19:640-7.

19. Yee T, Lechner AE, Boukus ER. The surge in urgent care centers: emergency department alternative or costly convenience? Res Brief 2013;26:1-6.

20. Perkins-Porras L, Whitehead DL, Strike PC, et al. Pre-hospital delay in patients with acute coronary syndrome: factors associated with patient decision time and home-to-hospital delay. Eur J Cardiovasc Nurs 2009;8:26-33.

21. Barr J, McKinley S, O'Brien E, et al. Patient recognition of and response to symptoms of TIA or stroke. Neuroepidemiology 2006;26:168-75.

22. Adrion ER, Aucott J, Lemke KW, et al. Health care costs, utilization and patterns of care following Lyme disease. PLoS One 2015;10:e0116767.

23. Johnson L, Aylward A, Stricker RB. Healthcare access and burden of care for patients with Lyme disease: a large United States survey. Health Policy 2011;102:64-71.

24. Johnson L, Wilcox S, Mankoff J, et al. Severity of chronic Lyme disease compared to other chronic conditions: a quality of life survey. PeerJ 2014;2:e322.

25. Cook MJ, Puri BK. Commercial test kits for detection of Lyme borreliosis: a meta-analysis of test accuracy. Int $J$ Gen Med 2016;9:427-40.

26. Waddell LA, Greig J, Mascarenhas M, et al. The Accuracy of Diagnostic Tests for Lyme Disease in Humans, A Systematic Review and Meta-Analysis of North American Research. PLoS One 2016;11:e0168613. 